\title{
La Lista Roja, una llamada de atención sobre el patrimonio en peligro
}

Hispania Nostra, asociación sin ánimo de lucro, se ha dedicado durante tres décadas a la defensa, salvaguarda y puesta en valor del Patrimonio Cultural Europeo y su entorno, en el ámbito de la sociedad civil. Ahora amplía sus herramientas para la defensa pública de aquellos lugares o monumentos de especial relevancia que se encuentran sujetos a cualquier tipo de riesgo, con la inclusión en su página Web de la sección denominada Lista Roja del Patrimonio, inaugurada en noviembre del pasado año.

El objetivo de la Lista Roja es sacar del olvido el patrimonio en peligro y concienciar sobre su valor
Desde que fue fundada en 1976, en sintonía con la organización paneuropea Europa Nostra, Hispania Nostra ha desempeñado, entre otras muchas funciones, y en coordinación con Academias y asociaciones de defensa del Patrimonio de carácter local, la de defensa pública de lugares en riesgo.

Su página Web, www.hispanianostra.es, no sólo recoge la actividad de la asociación, sus publicaciones, o noticias sobre patrimonio. Desde noviembre de 2006 cuenta con la sección titulada Lista Roja del Patrimonio que aspira a recoger todos aquellos elementos del patrimonio histórico español que se encuentren sometidos a riesgo de desaparición, destrucción o alteración esencial. La sección se compone de un mapa de España interactivo a través del cual se puede acceder, por Comunidades Autónomas, a las fichas y fotografías de los elementos patrimoniales en riesgo.

Actualmente se asiste a una mayor sensibilización pública en torno al Patrimonio, que se ha visto secundada con nuevas leyes protectoras

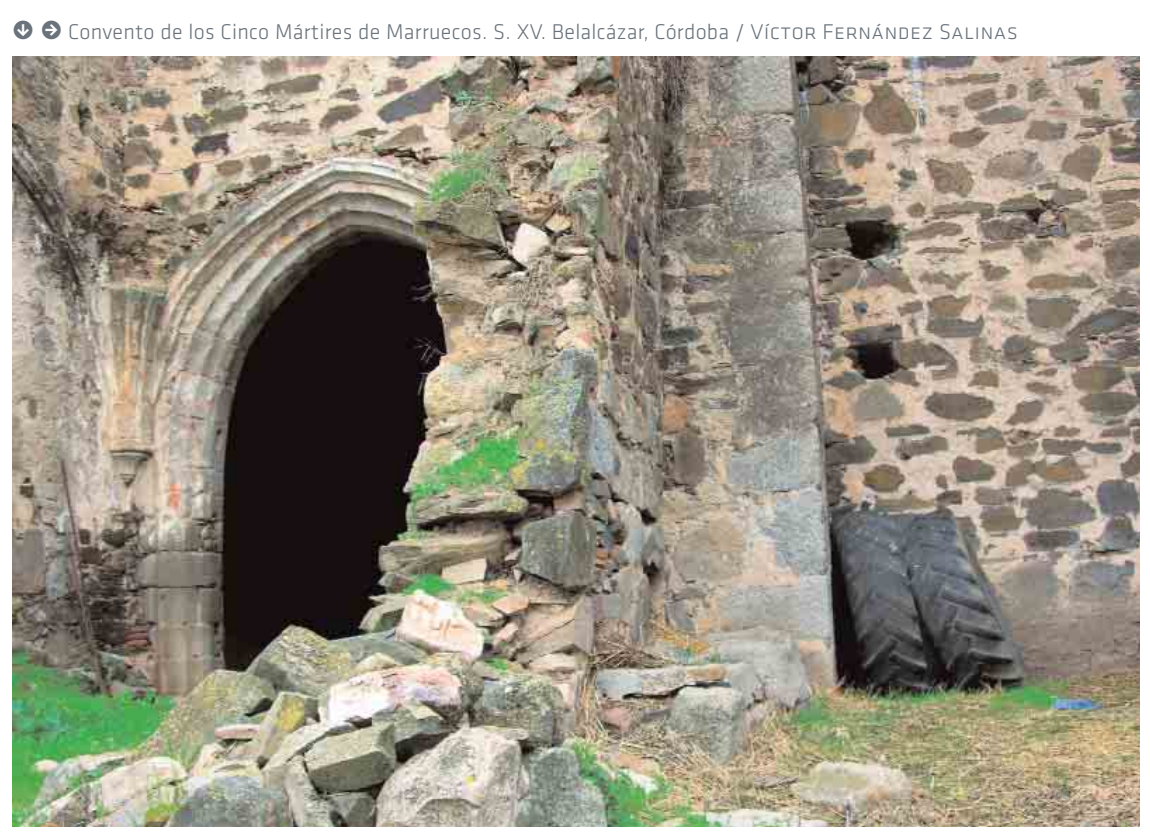


y de financiación. Entre ellas cabe destacar la brillante iniciativa conocida como el 1\% cultural. Pero, a pesar de este notable esfuerzo público y privado, la abundancia de monumentos, elementos y sitios de valor patrimonial impide que dichas actuaciones lleguen a todos

En este sentido, e igual que sucede en otros ámbitos, se producen notorias desigualdades, de las que es consciente Hispania Nostra. Los elementos que recoge la Lista Roja son los desfavorecidos por la fortuna, víctimas del olvido, y por ello se encuentran en tan penoso estado. Gran parte de estos monumentos en ruinas son de alto valor estético e histórico. Sus maltrechas piedras tienen, a veces, una capacidad de evocación superior a las de otros bien conservados, y encierran igual valor histórico y arquitectónico.

El objetivo de la Lista Roja, además de sacar a este sector del olvido mediante la difusión a través de Internet, es concienciar a la opinión pública, a propietarios -públicos y privados-, y a las entidades locales donde se encuentran esos elementos patrimoniales,

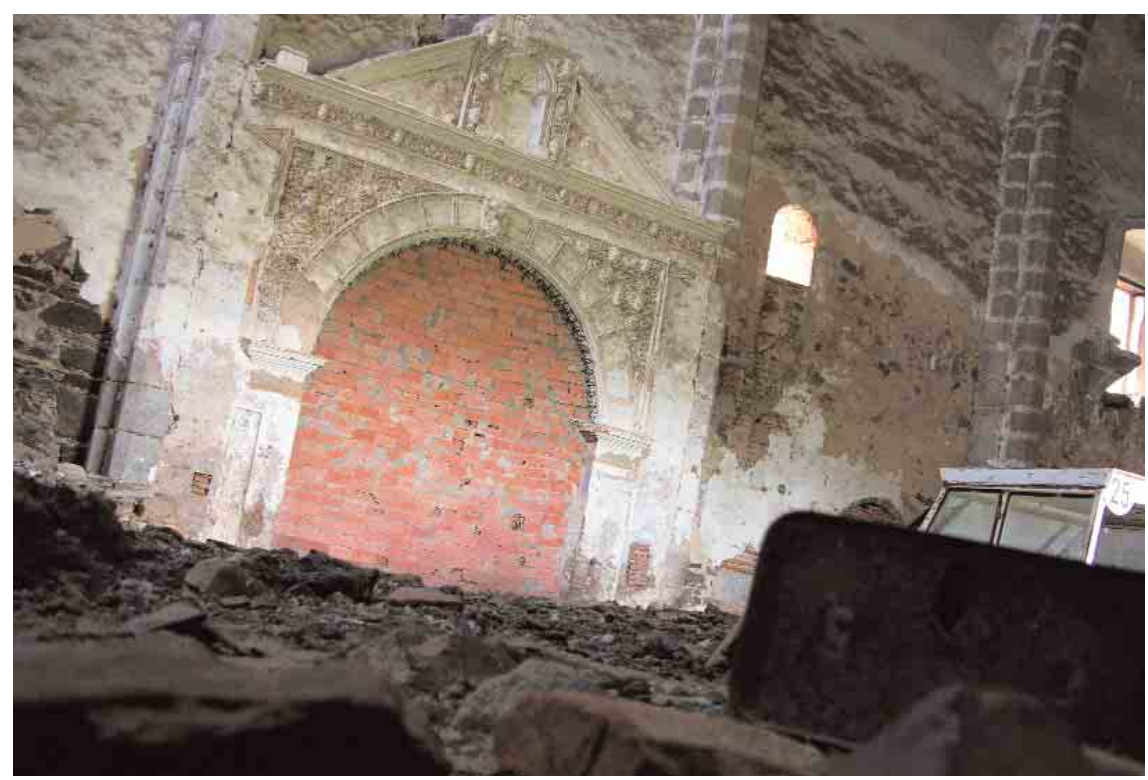

sobre su importante valor y sobre la necesidad de consolidarlos y mantenerlos. Igualmente aspira a evitar el expolio el saqueo. A estos efectos, pretende firmar acuerdos o convenios con las distintas escuelas de Arquitectura para que sus estudiantes realicen levantamientos de planos y descripciones de los elementos patrimoniales incluidos en la Lista Roja. Recientemente se ha firmado el primer acuerdo con la Escuela Superior de Arquitectura y Geodesia de la Universidad de Alcalá de Henares. Los expedientes realizados estarán a disposición de los municipios afectados para concienciar a sus habitantes sobre la necesidad de proteger su Patrimonio, aunque se encuentre en ruinas. También estarán a disposición del Grupo del Patrimonio Histórico y del Seprona de la Guardia Civil para facilitar la recuperación de elementos sustraídos.

Esta iniciativa necesita de la colaboración de todos. Hispania Nostra, que está recibiendo numerosas fichas remitidas por particulares y asociaciones, espera que la labor emprendida tenga un final feliz y que las bellezas en ruinas o en peligro sean preservadas para nuestro goce y el de posteriores generaciones.

Carlos Morenés y Mariátegui

Vicepresidente de Hispania Nostra 